\title{
The Comparison of Biocompatibility Properties between Ti Alloys and Fluorinated Diamond-Like Carbon Films
}

\author{
Chavin Jongwannasiri, ${ }^{1}$ Nutthanun Moolsradoo, ${ }^{2}$ Anak Khantachawana, ${ }^{1,3}$ \\ Pongpan Kaewtatip, ${ }^{1}$ and Shuichi Watanabe ${ }^{4}$ \\ ${ }^{1}$ Department of Mechanical Engineering, King Mongkut's University of Technology Thonburi, 126 Pracha-Utid Road, Bangmod, \\ Tungkru, Bangkok 10140, Thailand \\ ${ }^{2}$ Department of Tool and Materials Engineering, King Mongkut's University of Technology Thonburi, 126 Pracha-Utid Road, Bangmod, \\ Tungkru, Bangkok 10140, Thailand \\ ${ }^{3}$ Biological Engineering Program, King Mongkut's University of Technology Thonburi, 126 Pracha-Utid Road, Bangmod, Tungkru, \\ Bangkok 10140, Thailand \\ ${ }^{4}$ Department of Systems Engineering, Nippon Institute of Technology, 4-1 Gakuendai, Miyashiro Machi, Saitama 345-8501, Japan
}

Correspondence should be addressed to Anak Khantachawana, anak.kha@kmutt.ac.th

Received 6 December 2011; Revised 20 February 2012; Accepted 20 February 2012

Academic Editor: Amit Bandyopadhyay

Copyright ( $\odot 2012$ Chavin Jongwannasiri et al. This is an open access article distributed under the Creative Commons Attribution License, which permits unrestricted use, distribution, and reproduction in any medium, provided the original work is properly cited.

\begin{abstract}
Titanium and titanium alloys have found several applications in the biomedical field due to their unique biocompatibility. However, there are problems associated with these materials in applications in which there is direct contact with blood, for instance, thrombogenesis and protein adsorption. Surface modification is one of the effective methods used to improve the performance of $\mathrm{Ti}$ and $\mathrm{Ti}$ alloys in these circumstances. In this study, fluorinated diamond-like carbon (F-DLC) films are chosen to take into account the biocompatible properties compared with Ti alloys. F-DLC films were prepared on NiTi substrates by a plasma-based ion implantation (PBII) technique using acetylene $\left(\mathrm{C}_{2} \mathrm{H}_{2}\right)$ and tetrafluoromethane $\left(\mathrm{CF}_{4}\right)$ as plasma sources. The structure of the films was characterized by Raman spectroscopy. The contact angle and surface energy were also measured. Protein adsorption was performed by treating the films with bovine serum albumin and fibrinogen. The electrochemical corrosion behavior was investigated in Hanks' solution by means of a potentiodynamic polarization technique. Cytotoxicity tests were performed using MTT assay and dyed fluorescence. The results indicate that F-DLC films present their hydrophobic surfaces due to a high contact angle and low surface energy. These films can support the higher albumin-to-fibrinogen ratio as compared to Ti alloys. They tend to suppress the platelet adhesion. Furthermore, F-DLC films exhibit better corrosion resistance and less cytotoxicity on their surfaces. It can be concluded that F-DLC films can improve the biocompatibility properties of Ti alloys.
\end{abstract}

\section{Introduction}

Currently, biomaterials such as titanium and titanium alloys are widely used in biomedical applications, including instents, guide wires, and artificial joints. Previous investigation of diamond-like carbon (DLC) as a biomaterial has focused mainly on the biological performance of DLC coatings [1]. It has been shown that DLC is more biocompatible and wear-resistant than stainless steel [2], titanium, and $\mathrm{Ti}$ alloys $[3,4]$. Moreover, there have been several reports that cell adhesion on DLC films is related to surface energy and wettability [5-9]. These reports suggest that hydrophobic surfaces tend to inhibit blood cell adsorption. As for hydrophobic property, it is well known that fluorocarbon polymers present great water-shedding characteristics. Therefore, several research efforts have been made to synthesize superhydrophobic films, for instance, polytetrafluoroethylene- (PTFE-) coated medical devices have been utilized in clinical applications $[10,11]$. However, PTFE is not suitable for many other applications due to its weak mechanical properties.

Recently, as an alternative, fluorinated diamond-like carbon (F-DLC) films fabricated by doping fluorine during the formation of the DLC films have attracted much 
attention because they possess the high hydrophobicity of PTFE as well as excellent mechanical properties [12, 13]. Moreover, the studies reported that the F-DLC films possessed good antithrombogenicity [14-17]. In this study, F-DLC films, fabricated by plasma-based ion implantation (PBII) using $\mathrm{C}_{2} \mathrm{H}_{2}$ and $\mathrm{CF}_{4}$ as plasma sources, discussed the biocompatibility properties compared to Ti alloys.

\section{Materials and Methods}

2.1. Preparation of F-DLC Coatings. All specimens, namely, nickel-titanium (NiTi), commercially pure titanium (CP Ti), Ti-6Al-4V, and pure nickel (Ni), were cut to $10 \times 35 \mathrm{~mm}^{2}$. For all specimens, the $10 \times 35 \mathrm{~mm}^{2}$ surface was polished down to 2000 grit specification and mirror polished with 3 and $1 \mu \mathrm{m}$ diamond paste. NiTi was chosen to deposit the F-DLC film due to its widespread use as a biomaterial, for instance, in stents or guide wires. Other specimens were used to compare the biocompatibility properties with those of the coated F-DLC films. Fabrication of the FDLC films was carried out by PBII system which is shown schematically in Figure 1 . The vacuum chamber is $600 \times$ $630 \times 200 \mathrm{~mm}^{3}$ in size, with residual pressure approximately equal to $1 \times 10^{-4} \mathrm{~Pa}$. The plasma is generated by radio frequency $(13.6 \mathrm{MHz})$ and the negative high-voltage pulse power supply connected with the specimen holder. Prior to PBII, all titanium specimens were ultrasonically cleaned with acetone, methanol, and distilled water for $20 \mathrm{~min}$, respectively. The specimens were also sputter cleaned with $\mathrm{Ar}^{+}$for $20 \mathrm{~min}$ to remove surface residual contaminants and surface oxides using a negative-pulsed bias voltage of $10 \mathrm{kV}$. Using a negative pulsed bias voltage of $20 \mathrm{kV}$, the DLC film interlayer was first deposited with $\mathrm{CH}_{4}$ for $60 \mathrm{~min}$ to improve the adhesion between the film and the substrate. The deposition of the F-DLC films was performed at a negative-pulsed bias voltage of $5 \mathrm{kV}$, under gaseous mixtures of $\mathrm{C}_{2} \mathrm{H}_{2}$ and $\mathrm{CF}_{4}$ with the flow rate ratio at $2: 1$ and $1: 1$ for $180 \mathrm{~min}$. A pulse width of $5 \mu \mathrm{s}$, a pulse delay of $25 \mu \mathrm{s}$, and a pulse frequency of $1 \mathrm{kHz}$ were also utilized during the coating process. The deposition pressure was set to $2 \mathrm{~Pa}$, and the total deposited thickness of the films was approximately $500 \mathrm{~nm}$.

2.2. Characterization of the Film Structure. The structure of the F-DLC films was analyzed by Raman spectroscopy (JASCO NRS-1000 DT) at an excitation wavelength of $532 \mathrm{~nm}$ and with a spot size of $4 \mu \mathrm{m}$. Raman spectroscopy is a fast and nondestructive tool for characterization of amorphous carbons. All carbons demonstrate common features in their Raman spectra in the $800-2000 \mathrm{~cm}^{-1}$ region, the so-called D and G peaks, which lie at approximately 1360 and $1560 \mathrm{~cm}^{-1}$, respectively $[18,19]$. The D peak represents the breathing modes of $\mathrm{sp}^{2}$ atoms in rings. The $\mathrm{G}$ peak is caused by the bond stretching of all pairs of $\mathrm{sp}^{2}$ atoms in both rings and chains $[18,20]$. The Raman spectra were fitted with Gaussian line shapes, and the background was subtracted. All fitting parameters were recorded to characterize the structure of the films.

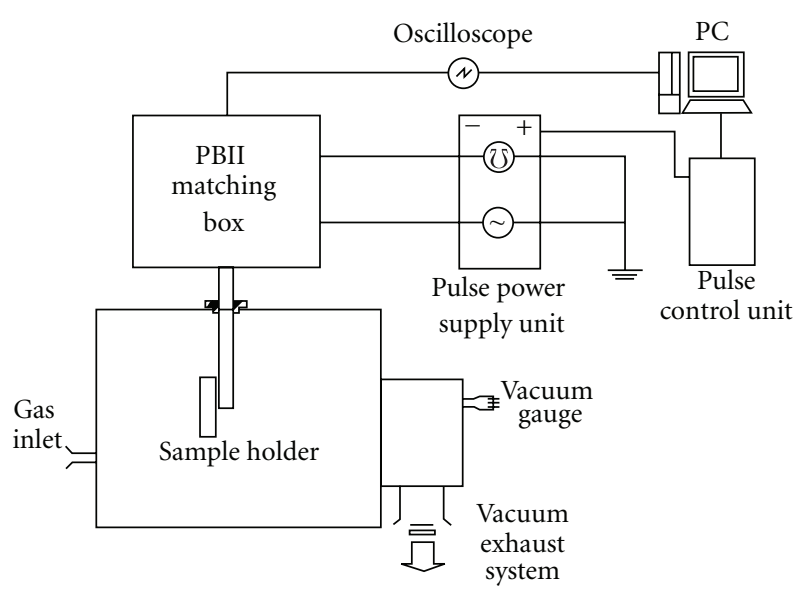

FIGURE 1: Schematic of the PBII apparatus used in this experiment.

TABLE 1: Surface energy data of liquids used for calculation.

\begin{tabular}{lcccc}
\hline \multirow{2}{*}{ Liquid } & \multicolumn{4}{c}{ Surface energy $(\mathrm{mN} / \mathrm{m})$} \\
& $\gamma^{d}$ & $\gamma^{p}$ & $\gamma^{h}$ & $\gamma^{T}$ \\
\hline Distilled water & 29.1 & 1.3 & 42.4 & 72.8 \\
Ethylene glycol & 30.1 & 0 & 17.6 & 47.7 \\
Diiodomethane & 46.8 & 4 & 0 & 50.8 \\
\hline
\end{tabular}

$\gamma^{d}$ : dispersion force component, $\gamma^{p}$ : polar force component, $\gamma^{h}$ : hydrogenbonding force component, $\gamma^{T}$ : total surface energy.

2.3. Contact Angle Measurement and Surface Energy Calculation. The contact angle $(\theta)$ was measured under atmospheric conditions at room temperature with a contact angle meter (Kyowa Interface Science Co., Ltd.) using distilled water, ethylene glycol, and diiodomethane as the tested liquids. A droplet of the tested liquids with a volume of $1 \mu \mathrm{L}$ was released onto the surface of a specimen. For each surface, at least five droplets were measured. The surface energy of the specimen was calculated based on the measured contact angles using the extended Fowkes theory according to Kitazaki and Hata $[21,22]$ as shown in

$$
\left(\begin{array}{c}
\sqrt{\gamma_{s}^{d}} \\
\sqrt{\gamma_{s}^{p}} \\
\sqrt{\gamma_{s}^{h}}
\end{array}\right)=\left(\begin{array}{ccc}
\sqrt{\gamma_{L, A}^{d}} & \sqrt{\gamma_{L, A}^{p}} & \sqrt{\gamma_{L, A}^{h}} \\
\sqrt{\gamma_{L, B}^{d}} & \sqrt{\gamma_{L, B}^{p}} & \sqrt{\gamma_{L, B}^{h}} \\
\sqrt{\gamma_{L, C}^{d}} & \sqrt{\gamma_{L, C}^{p}} & \sqrt{\gamma_{L, C}^{h}}
\end{array}\right)^{-1}\left(\begin{array}{c}
\gamma_{L, A} \frac{\left(1+\cos \theta_{A}\right)}{2} \\
\gamma_{L, B} \frac{\left(1+\cos \theta_{B}\right)}{2} \\
\gamma_{L, C} \frac{\left(1+\cos \theta_{C}\right)}{2}
\end{array}\right),
$$

where $\gamma_{S}$ and $\gamma_{L}$ are the surface energy of the solid and the liquid, and the superscripts $d, p$, and $h$ refer to the dispersion force, polar force, and hydrogen-bonding force components, respectively. In (1), $A, B$, and $C$ represent the three liquids used in the experiment. $A$ is distilled water, $B$ is ethylene glycol, and $C$ is diiodomethane. The surface energy data of the liquids used for calculation by the extended Fowkes theory are shown in Table 1. The contact angles for each of the liquids are represented by $\cos \theta$.

2.4. Protein Adsorption Test. Plasma protein adsorption tests were performed by treating the specimen with bovine serum 
TABLE 2: Chemical components of Hanks' solution.

\begin{tabular}{lc}
\hline Component & Concentration $(\mathrm{g} / \mathrm{L})$ \\
\hline $\mathrm{CaCl}_{2} \cdot 2 \mathrm{H}_{2} \mathrm{O}$ & 0.185 \\
$\mathrm{KCl}$ & 0.4 \\
$\mathrm{KH}_{2} \mathrm{PO}_{4}$ & 0.06 \\
$\mathrm{MgCl}_{2} \cdot 6 \mathrm{H}_{2} \mathrm{O}$ & 0.1 \\
$\mathrm{MgSO}_{4} \cdot 7 \mathrm{H}_{2} \mathrm{O}$ & 0.1 \\
$\mathrm{NaCl}$ & 8 \\
$\mathrm{NaHCO}_{3}$ & 0.35 \\
$\mathrm{Na}_{2} \mathrm{HPO}_{4} \cdot 2 \mathrm{H}_{2} \mathrm{O}$ & 0.06 \\
$\mathrm{D}$-glucose & 1 \\
Phenol red & 0.01 \\
\hline
\end{tabular}

albumin (BSA, Sigma-Aldrich, St. Louis, MO, USA) and fibrinogen (Sigma-Aldrich, St. Louis, MO, USA). The specimen was initially incubated with $5 \%$ sodium dodecyl sulfate (SDS) for 12 hours to completely remove protein contamination. After incubation, three cloning cylinders $(0.6 \mathrm{~mm}$ diameter) were sealed on the specimen using parafilm. Following the sealing procedure, $100 \mu \mathrm{L}$ of BSA $(0.25 \mathrm{mg} / \mathrm{mL})$ was added into each cloning cylinder and the specimen was incubated at $37^{\circ} \mathrm{C}$ for $60 \mathrm{~min}$. After incubation, $10 \mu \mathrm{L}$ of the BSA $(0.25 \mathrm{mg} / \mathrm{mL})$ was transferred into the 96 -well plate, and then its concentration was determined using a Bradford protein assay (Bio-Rad, Hercules, CA, USA). The solution was then incubated at room temperature for $60 \mathrm{~min}$ before the absorbance at $595 \mathrm{~nm}$ was measured using a microplate reader (Infinite 200 Tecan, Austria). The concentration of each protein was calibrated using the corresponding standard curve. The absorbed protein amount was determined by subtracting the nonadsorbed protein amount from the initial protein amount. Measurements were performed in triplicate for each cloning cylinder. The adsorption of fibrinogen was also measured using the same procedure.

2.5. Electrochemical Corrosion Behavior. Corrosion resistance was measured with a standard three-electrode electrochemical cell. A saturated calomel electrode (SCE) was used as the reference electrode with a graphite counter electrode. The potentiodynamic experiment was conducted using a computer-controlled potentiostat (PGSTAT302N, AUTOLAB). The specimen was pressed into a holder with a PTFE gasket, which ensured that only the front part of the specimen would come in contact with the electrolyte. The corrosion resistance was examined in a Hanks' solution at $37 \pm 0.2^{\circ} \mathrm{C}$ ( $\mathrm{pH}$ 7.4). The composition of the Hanks' solution is given in Table 2. After the specimen had been immersed in the experimental solution for an hour under open-circuit conditions, polarization experiments were conducted at a rate of $20 \mathrm{mV} / \mathrm{min}$.

2.6. Cytotoxicity Test. Two methods were employed to test the cytotoxicity of these alloys. The cytotoxicity of the specimen was first evaluated using the Dulbecco modified eagle medium (DMEM, Invitrogen, OR, USA) dilution method. L929 fibroblast cells (mouse fibroblasts) at a density of 2,000 cells/well grown on a 96-well plate were cultured with an

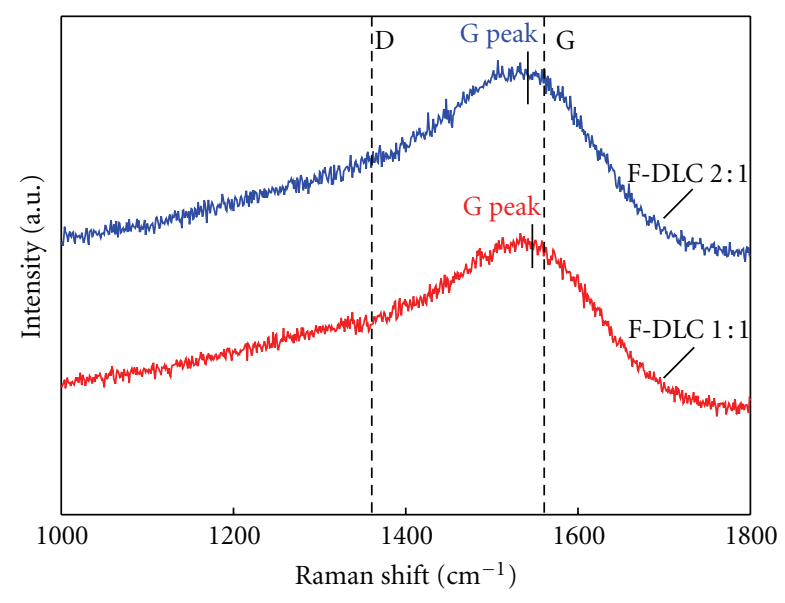

FIgURE 2: Raman spectra of the F-DLC films.

extraction medium obtained from the incubated specimen with DMEM for 7 days at $37^{\circ} \mathrm{C}$. The cell viability was determined using the MTT (3-(4,5-dimethylthiazol-2-yl)-2,5diphenyltetrazolium bromide) assay following the standard procedure (Molecular Probes, V-13154). The absorbance at $570 \mathrm{~nm}$ of formazan was measured using a microplate reader (Infinite 200 Tecan, Austria). Measurements were performed in triplicate on cells seeded onto a 96-well plate, and the percentage of cell viability was measured daily.

In the second method, L929 fibroblast cells were cultured on the specimen. The culture was incubated with a fluorescence probe, following the standard procedure (Molecular Probes, L-3224). The specimen was then immediately viewed using fluorescence microscopy (Olympus BX60, Center Valley, PA, USA). Images were acquired using a 40x objective lens.

\section{Results and Discussion}

3.1. Film Structure by Raman Spectroscopy. A previous study [23] reported that F-DLC films deposited using a negative pulsed bias voltage of $5 \mathrm{kV}$ and a gas flow rate ratio of $\mathrm{C}_{2} \mathrm{H}_{2}: \mathrm{CF}_{4}$ at $2: 1$ and $1: 1$ have better hardness, good adhesive strength, and a lower friction coefficient as compared to those deposited at $15 \mathrm{kV}$ and equivalent gas flow rate ratio. Therefore, the F-DLC films at a negative-pulsed bias voltage of $5 \mathrm{kV}$ and gas flow rate ratio of $\mathrm{C}_{2} \mathrm{H}_{2}: \mathrm{CF}_{4}$ at $2: 1$ and $1: 1$ (represented F-DLC $2: 1$ and F-DLC $1: 1$ ) were chosen to deposit and evaluate the biocompatibility properties of F-DLC films.

The Raman spectra of the F-DLC films are shown in Figure 2. The results show the Raman spectra of F-DLC 2:1 and F-DLC $1: 1$. The position of the G peak is related to the bond-angle disorder or the $\mathrm{sp}^{3}$ bonding content, while the $\mathrm{I}_{\mathrm{D}} / \mathrm{I}_{\mathrm{G}}$ ratio is proportional to the ratio of $\mathrm{sp}^{2} / \mathrm{sp}^{3}[24,25]$. These two factors play a major role in determining the Raman spectra. In particular, the ratio of $\mathrm{sp}^{2} / \mathrm{sp}^{3}$ is one of the most important factors governing the quality of the DLC films. Generally, the likelihood that the properties of the DLC films resemble those of diamond increases when this ratio is low. From Figure 2, the F-DLC films fabricated in 
TABLE 3: Contact angle and surface energy of uncoated compared with coated specimens.

\begin{tabular}{lcccccc}
\hline \multirow{2}{*}{ Specimen } & & Contact angle $\left(^{\circ}\right)$ & & \multicolumn{3}{c}{ Surface energy $(\mathrm{mN} / \mathrm{m})$} \\
& Distilled water & Ethylene glycol & Diiodomethane & $\gamma^{d}$ & $\gamma^{p}$ & $\gamma^{h}$ \\
\hline CP Ti & 80.4 & 58.0 & 50.1 & 29.2 & 5.6 & 2.7 \\
Ti-6Al-4V & 79.3 & 57.5 & 45.7 & 29.8 & 8.4 & 2.6 \\
NiTi & 84.5 & 59.1 & 49.9 & 32.4 & 2.0 & 1.4 \\
NiTi-coated F-DLC 2:1 & 81.4 & 50.9 & 24.5 & 43.3 & 3.1 & 0.4 \\
NiTi-coated F-DLC 1:1 & 85.3 & 55.5 & 32.2 & 41.7 & 1.8 & 0.8 \\
\hline
\end{tabular}

$\gamma^{d}$ : dispersion force component, $\gamma^{p}$ : polar force component, $\gamma^{h}$ : hydrogen-bonding force component, $\gamma^{T}$ : total surface energy.

this experiment demonstrate a broad spectrum composed of a D band $\left(1360 \mathrm{~cm}^{-1}\right)$ and a $\mathrm{G}$ band $\left(1560 \mathrm{~cm}^{-1}\right)$ similar to the peaks observed in conventional DLC films. The G peak of the F-DLC films shifts from $1542 \mathrm{~cm}^{-1}$ (F-DLC $2: 1$ ) to $1546 \mathrm{~cm}^{-1}$ (F-DLC $1: 1$ ), while the $\mathrm{I}_{\mathrm{D}} / \mathrm{I}_{\mathrm{G}}$ ratio increases from 0.47 to 0.50 with an increase in the fluorine content. The microstructure is altered due to an increase in fluorine content because the $\mathrm{G}$ peak position shifts to a higher level, while the $I_{D} / I_{G}$ ratio increases. These results indicate an increase in the number or the size of graphitic domains [26], that is, an increase of $\mathrm{sp}^{2}$ bonds (a decrease in $\mathrm{sp}^{3}$ bonds) and the formation of $\mathrm{sp}^{2}$ clusters.

3.2. Contact Angle and Surface Energy. Contact angle and surface energy have great potential utility. They can characterize and predict the wettability of materials. The contact angle and surface energy results of uncoated $\mathrm{Ti}$ alloys and coated F-DLC films are shown in Table 3. Both uncoated and coated F-DLC films demonstrate a hydrophobic surface with a water contact angle of approximately $80^{\circ}$, while the surface energy values of the F-DLC films are higher than those of the uncoated specimens. This phenomenon may occur due to the higher surface roughness of the films. Owing to fluorine incorporation, the films become more hydrophobic with a reduction in surface energy. The total surface energy $\left(\gamma^{T}\right)$ of the F-DLC films is estimated as the sum of the dispersion component, the polar component, and the hydrogen-bonding component. As the fluorine content in the DLC films increased, the total surface energy decreased $(46.8 \mathrm{mN} / \mathrm{m}$ to $43.7 \mathrm{mN} / \mathrm{m})$. The reduction in the surface energy was largely ascribed to the decrease in the dispersion component. It is mainly caused by the decrease of $-\mathrm{C}-$ $\mathrm{CF}$ bonds and the increase of $-\mathrm{CF}$ and $-\mathrm{CF}_{2}$ bonds on the surface, and therefore the reduced surface energy of the film $[27,28]$. The surface energy is influenced by the difference in the forces between atoms and molecules at the interface [29]. The polar component is controlled by several intermolecular forces, permanent and induced dipoles, and hydrogen bonds $[29,30]$. The hydrogen bonding force is an indicator of the ability to form hydrogen bonds at the surface. The wettability, that is, hydrophobic or hydrophilic, is also related to the hydrogen bonding at the surface [31]. In general, the wettability of a surface is controlled by the chemical structure of the film at the surface and the surface roughness. However, Yao et al. reported that the chemical structure of the film is a more dominating factor as compared to the surface roughness in influencing the surface energy of F-DLC [32]. The increase in hydrophobicity of the FDLC was attributed not only to the higher incorporation of fluorine but also mostly to the presence of $\mathrm{CF}_{n}$ groups on the surface [13].

3.3. Biocompatibility Test by Protein Adsorption Measurement. When an artificial surface is in contact with blood flow, quick adsorption of plasma proteins occurs. Platelets adhere to the implant via a layer of adsorbed proteins [33-35]. The rate and extensiveness of this process depend on the type of proteins adsorbed on the surface of the biomaterial [33-35]. Usually, the first proteins that are adsorbed on the surface of the biomaterial are albumin, fibrinogen, and fibronectin. The adsorption of albumin retards the adhesion and activation of platelets, while the adsorption of fibrinogen promotes platelet adhesion and activation. The adsorbed fibrinogen is converted into insoluble fibrin polymer, which finally results in the formation of a thrombus [36, 37]. Dion et al. reported that the ratio of albumin to fibrinogen is important when assessing the adhesion of blood platelets to artificial surfaces and that a higher ratio indicates a lower number of adhering platelets [38, 39].

In this study, Figures 3(a) and 3(b) show the protein albumin and fibrinogen adsorption results for uncoated Ti alloys and coated F-DLC films. It is clearly observed from Figure 3 that the F-DLC films exhibit higher albumin adsorption and lower fibrinogen adsorption than the uncoated specimens. The albumin-to-fibrinogen ratio in coated specimens, as shown in Figure 4, indicates that the FDLC films can prevent the formation of a thrombus better than the uncoated specimens. It is well known that surface physics (surface topography and surface energy) influences the cellular response [40]. Ma et al. reported that higher surface energy results in enhanced cell viability and increased albumin-to-fibrinogen adsorption ratio [36]. The results in Table 3 comply to the findings of $\mathrm{Ma}$ et al.; that is, higher surface energy results in an increased albumin-to-fibrinogen ratio, which causes reduced thrombosis formation [41-43].

3.4. Electrochemical Corrosion Behavior. The term "biocompatibility" may be simply defined as the ability of a material to be accepted by the body. Because all materials generate a "foreign body reaction" when implanted in the body, the degree of biocompatibility is related to the extent of this reaction. Therefore, biocompatibility is directly related to the corrosion behavior of the material and its tendency to release potential toxic ions [44]. 


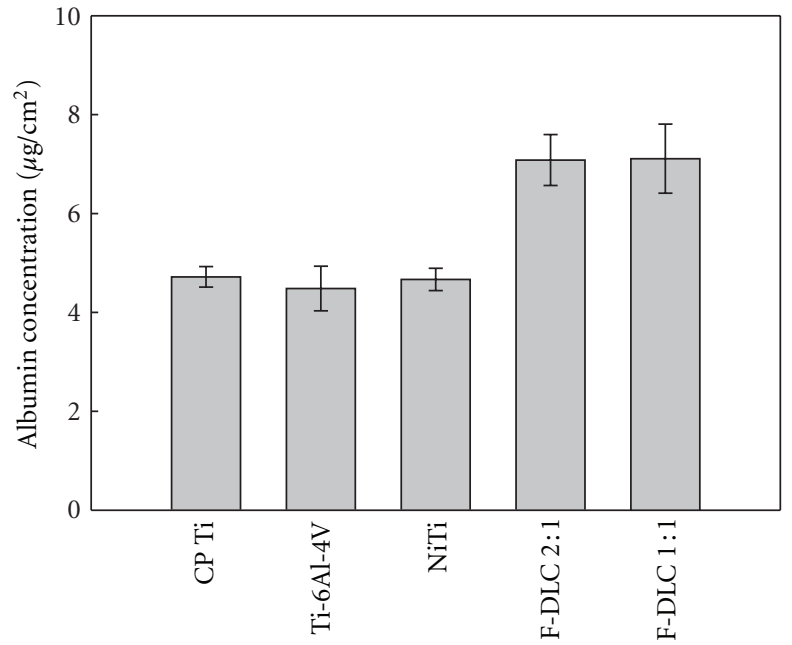

(a)

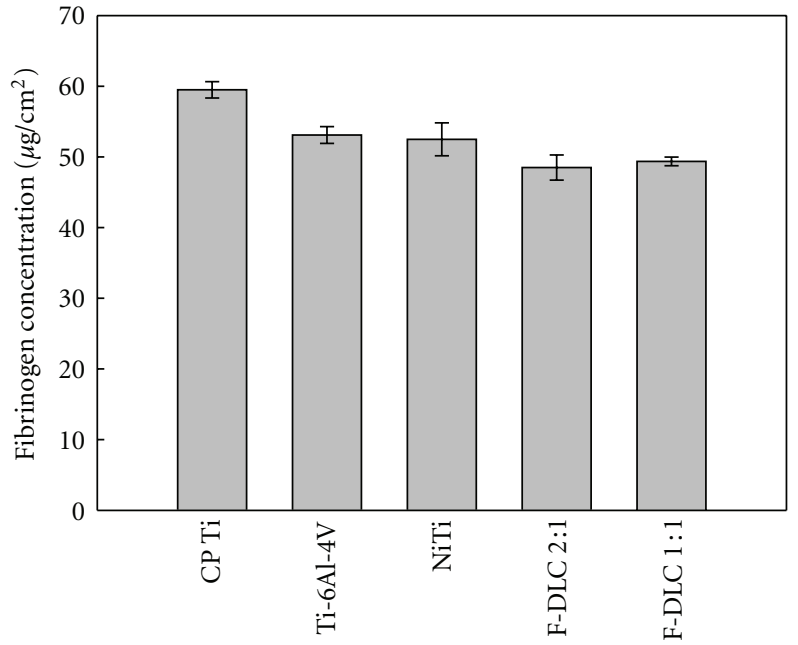

(b)

FIgURE 3: The adsorption of (a) albumin protein and (b) fibrinogen protein between Ti alloys and F-DLC films.

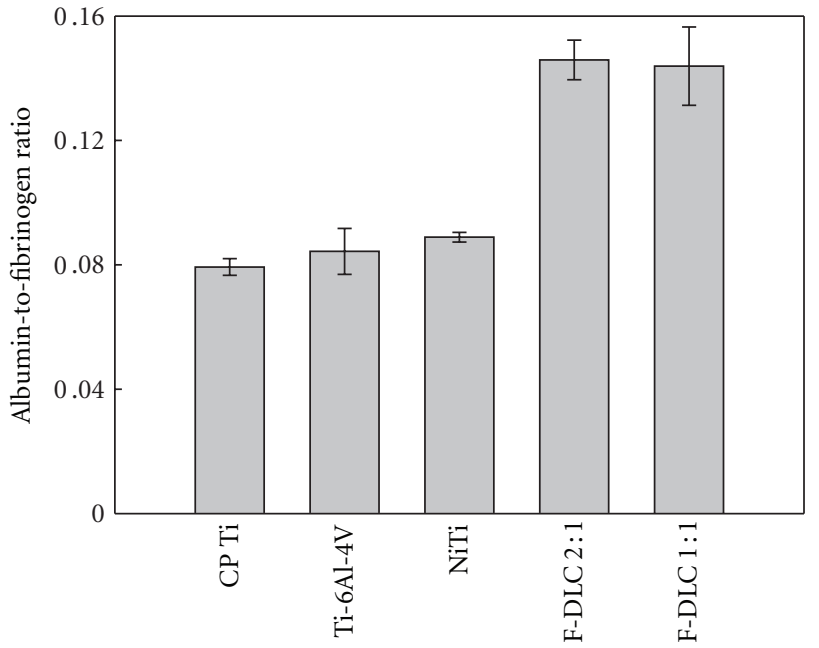

FIgURE 4: The ratio of albumin to fibrinogen adsorption between Ti alloys and F-DLC films.

Figure 5 shows the potentiodynamic polarization curves of Ti alloys and F-DLC films in Hanks' solution. In general, the samples with a lower current density and a higher potential indicate better corrosion resistance. It can be clearly observed from a shift of the whole polarization curve towards the region of lower current density and higher potential that F-DLC films significantly improve the corrosion resistance of the Ti alloys. For the F-DLC films, the whole polarization curve moves to the region of higher potential and lower current density with an increase in the fluorine content, indicating that the corrosion resistance of the F-DLC films increases with increasing fluorine content. Additionally, the polarization curves of F-DLC films indicate the unstable value. These results are mainly due to the high surface roughness of the films.

The enhancement in the corrosion resistance of the coated specimens may be attributed to the reduced electrical

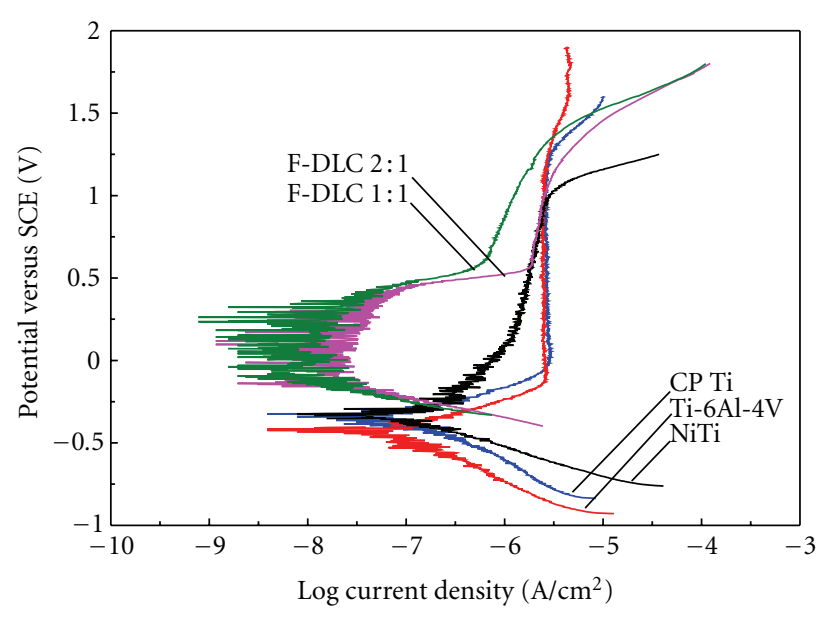

FIGURE 5: The potentiodynamic polarization curves of Ti alloys and F-DLC films.

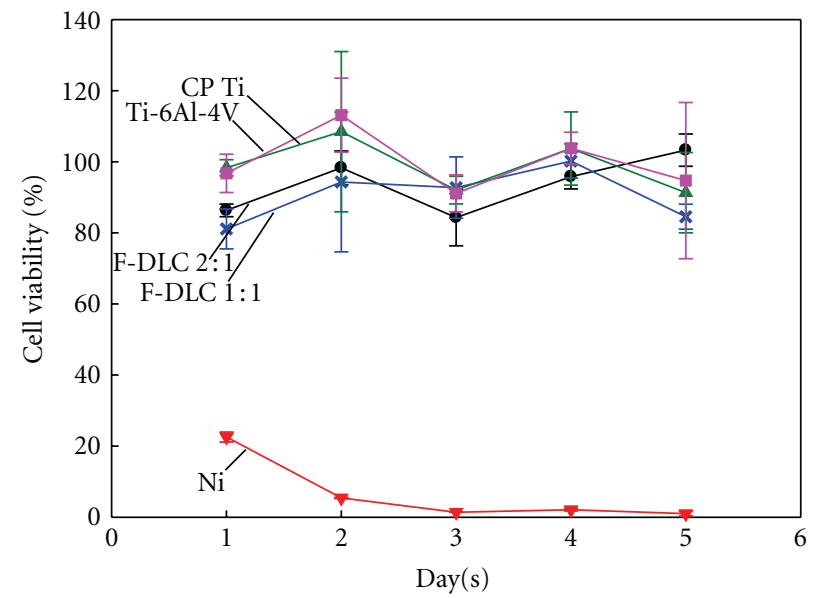

FIgure 6: The cell viability of Ti alloys and F-DLC films based on $\mathrm{Ni}$, using DMEM dilution method. 


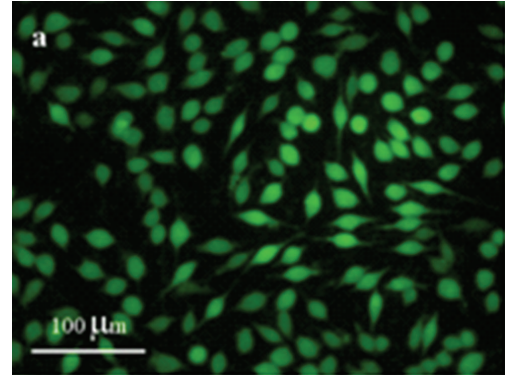

(a)

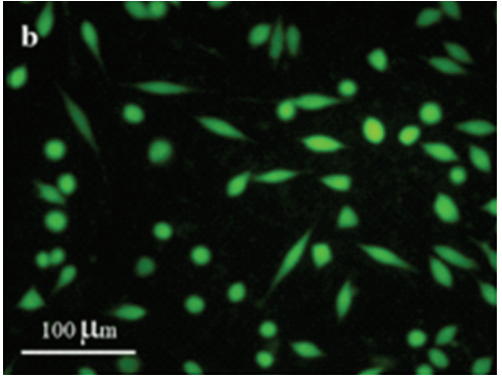

(b)

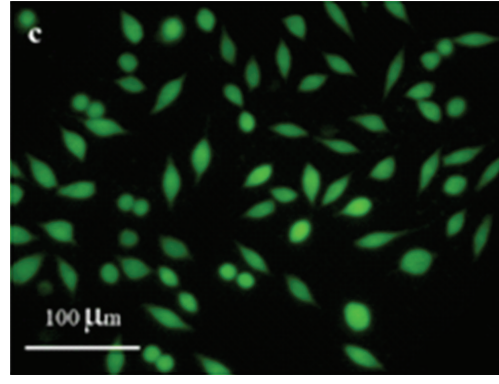

(c)

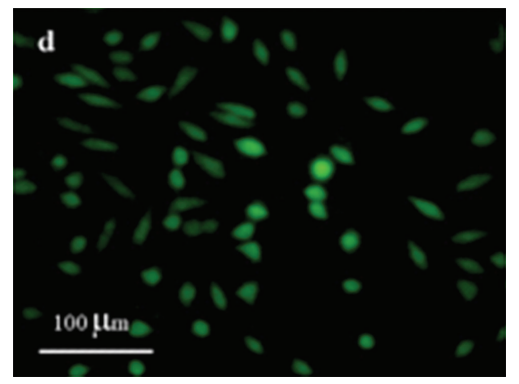

(d)

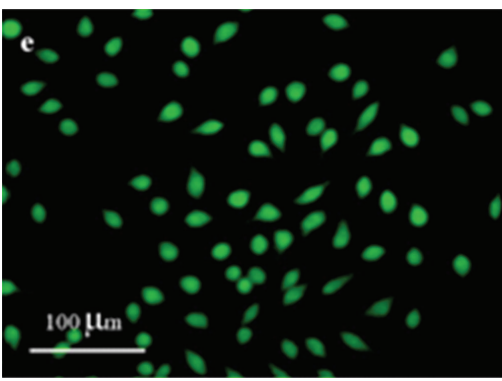

(e)

FIgure 7: Morphology of L929 fibroblast cell attached on (a) F-DLC 2: 1, (b) F-DLC 1:1, (c) NiTi, (d) CP Ti, and (e) Ti-6Al-4 V captured by fluorescence microscope using a 40x objective lens.

conductivity caused by the chemical inertness of the FDLC films in comparison to the uncoated specimens. The low electrical conductivity of the F-DLC films reduces the electron transport and the electrical charge exchange at the surface, which are the cause of the electrochemical corrosion [45]. Thus, the F-DLC films can act as a passive barrier to prevent aggressive ions in the corrosion solution from attacking the Ti alloy substrates.

3.5. Cytotoxicity. A cytotoxicity test is a screening method to determine whether a material has any toxic effect on living cells due to leachable components before employing it in a medical device. Figure 6 shows the cytotoxicity of specimens compared with $\mathrm{NiTi}$, which was proven to be highly biocompatible due to the formation of a passive titanium oxide layer $\left(\mathrm{TiO}_{2}\right)[46,47]$ similar to that found on Ti alloys [48]. It is clearly observed from Figure 7 that there was no difference in the viability of L929 fibroblast cells among the specimens except for pure nickel (Ni). The L929 fibroblast cells grown on Ti alloys and F-DLC films had approximate viabilities between 80 and $110 \%$ along the experiment, but $\mathrm{Ni}$ had viability below $2-20 \%$. There was no indication that the F-DLC coating was dissolved or toxic to the L929 fibroblast cells because there was no loss of cell integrity due to the coating. These results from the cytotoxicity experiments showed that the F-DLC coating provides a nontoxic surface on which the L929 fibroblast cells were able to attach, grow, and divide in a normal manner, as shown in the fluorescence microscopy (Figure 7). Furthermore, $\mathrm{Ma}$ et al. reported that the surface energy increased with increasing surface roughness resulting in enhanced cell viability [36]. In this experiment, however, the
TABLE 4: Average surface roughness of specimens.

\begin{tabular}{lc}
\hline Specimen & Average roughness $(\mathrm{Ra}, \mu \mathrm{m})$ \\
\hline $\mathrm{CP}$ Ti & 0.098 \\
Ti-6Al-4V & 0.123 \\
NiTi & 0.089 \\
NiTi-coated F-DLC 2:1 & 0.259 \\
NiTi-coated F-DLC 1:1 & 0.249 \\
\hline
\end{tabular}

surface roughness of the Ti alloys and the F-DLC films was in the range $0.1-0.3 \mu \mathrm{m}$ (Table 4 ) which was not significantly different. Additionally, the surface chemistry (fluorine content) had no effect on cell viability and attachment because there was no anomaly in cell characteristics, as shown in Figure 7. Due to the aforementioned reasons, the surface roughness, surface energy, and surface chemistry did not influence cytotoxicity on the surface of the Ti alloys and the F-DLC films.

\section{Conclusion}

Fluorinated diamond-like carbon (F-DLC) films were successfully prepared on Ti alloys by the PBII technique. The films were investigated for their biocompatibility properties using contact angle measurement, protein adsorption, corrosion behavior, and cytotoxicity. F-DLC films possess a hydrophobic surface due to an increase in the contact angle. Though it is expected that the surface energy should decrease in comparison with the uncoated specimens, it demonstrates higher values. This may have occurred due to the higher surface roughness of the films. In addition, 
the F-DLC films possess a higher albumin-to-fibrinogen ratio than the uncoated specimens, which indicates that the films can suppress platelet adhesion preventing thrombosis on their surfaces. F-DLC films also exhibit better corrosion resistance than the uncoated specimens due to their lower electrical conductivity and their chemical inertness. Due to the aforementioned reasons, the F-DLC films seem to be highly biocompatible with less cytotoxicity than uncoated specimens. F-DLC films can thus be of great significance when used in biomedical applications.

\section{Acknowledgments}

This work was supported by the Higher Education Research Promotion and National Research University Project of Thailand, Office of the Higher Education Commission, a grant from the National Metal and Materials Technology Center (MTEC), a grant from the National Science and Technology Development Agency (NSTDA) and a grant from the Thailand Research Fund (TRF).

\section{References}

[1] P. D. Maguire, J. A. McLaughlin, T. I. T. Okpalugo et al., "Mechanical stability, corrosion performance and bioresponse of amorphous diamond-like carbon for medical stents and guidewires," Diamond and Related Materials, vol. 14, no. 8, pp. 1277-1288, 2005.

[2] P. Firkins, J. L. Hailey, J. Fisher, A. H. Lettington, and R. Butter, "Wear of ultra-high molecular weight polyethylene against damaged and undamaged stainless steel and diamond-like carbon-coated counterfaces," Journal of Materials Science, vol. 9, no. 10, pp. 597-601, 1998.

[3] M. Mohanty, T. V. Anilkumar, P. V. Mohanan et al., "Long term tissue response to titanium coated with diamond like carbon," Biomolecular Engineering, vol. 19, no. 2-6, pp. 125-128, 2002.

[4] T. V. Kumari, P. R. A. Kumar, C. V. Muraleedharan et al., "In vitro cytocompatibility studies of Diamond Like Carbon coatings on titanium," Bio-Medical Materials and Engineering, vol. 12, no. 4, pp. 329-338, 2002.

[5] M. I. Jones, I. R. McColl, D. M. Grant, K. G. Parker, and T. L. Parker, "Haemocompatibility of DLC and TiC-TiN interlayers on titanium," Diamond and Related Materials, vol. 8, no. 2-5, pp. 457-462, 1999.

[6] M. I. Jones, I. R. McColl, D. M. Grant, K. G. Parker, and T. L. Parker, "Protein adsorption and platelet attachment and activation, on TiN, TiC, and DLC coatings on titanium for cardiovascular applications," Journal of Biomedical Materials Research, vol. 52, no. 2, pp. 413-421, 2000.

[7] N. Nurdin, P. François, Y. Mugnier et al., "Haemocompatibility evaluation of DLC- and SiC-coated surfaces," European Cells and Materials, vol. 5, pp. 17-28, 2003.

[8] T. I. T. Okpalugo, A. A. Ogwu, P. D. Maguire, and J. A. D. McLaughlin, "Platelet adhesion on silicon modified hydrogenated amorphous carbon films," Biomaterials, vol. 25, no. 2, pp. 239-245, 2004.

[9] P. Yang, N. Huang, Y. X. Leng et al., "Activation of platelets adhered on amorphous hydrogenated carbon (a-C:H) films synthesized by plasma immersion ion implantationdeposition (PIII-D)," Biomaterials, vol. 24, no. 17, pp. 2821-2829, 2003.
[10] J. A. McLaughlin, B. Meenan, P. Maguire, and N. Jamieson, "Properties of diamond like carbon thin film coatings on stainless steel medical guidewires," Diamond and Related Materials, vol. 5, no. 3-5, pp. 486-491, 1996.

[11] R. S. Benson, "Use of radiation in biomaterials science," Nuclear Instruments and Methods in Physics Research, Section $B$, vol. 191, no. 1-4, pp. 752-757, 2002.

[12] C. Donnet, "Recent progress on the tribology of doped diamond-like and carbon alloy coatings: a review," Surface and Coatings Technology, vol. 100-101, no. 1-3, pp. 180-186, 1998.

[13] R. S. Butter, D. R. Waterman, A. M. Lettington, R. T. Ramos, and E. J. Fordham, "Production and wetting properties of fluorinated diamond-like carbon coatings," Thin Solid Films, vol. 311, no. 1-2, pp. 107-113, 1997.

[14] T. Saito, T. Hasebe, S. Yohena et al., "Antithrombogenicity of fluorinated diamond-like carbon films," Diamond and Related Materials, vol. 14, no. 3-7, pp. 1116-1119, 2005.

[15] T. Hasebe, S. Yohena, A. Kamijo et al., "Fluorine doping into diamond-like carbon coatings inhibits protein adsorption and platelet activation," Journal of Biomedical Materials Research, vol. 83, no. 4, pp. 1192-1199, 2007.

[16] T. Hasebe, A. Shimada, T. Suzuki et al., "Fluorinated diamondlike carbon as antithrombogenic coating for blood-contacting devices," Journal of Biomedical Materials Research, vol. 76, no. 1, pp. 86-94, 2006.

[17] T. Hasebe, S. Nagashima, A. Kamijo et al., "Depth profiling of fluorine-doped diamond-like carbon (F-DLC) film: localized fluorine in the top-most thin layer can enhance the nonthrombogenic properties of F-DLC," Thin Solid Films, vol. 516, no. 2-4, pp. 299-303, 2007.

[18] A. C. Ferrari and J. Robertson, "Interpretation of Raman spectra of disordered and amorphous carbon," Physical Review B, vol. 61, no. 20, pp. 14095-14107, 2000.

[19] A. C. Ferrari and J. Robertson, "Resonant raman spectroscopy of disordered, amorphous, and diamondlike carbon," Physical Review B, vol. 64, no. 7, Article ID 075414, 13 pages, 2001.

[20] S. Piscanec, M. Lazzeri, F. Mauri, A. C. Ferrari, and J. Robertson, "Kohn anomalies and electron-phonon interactions in graphite," Physical Review Letters, vol. 93, no. 18, Article ID 185503, 4 pages, 2004.

[21] Y. Kitazaki and T. Hata, "Surface-chemical criteria for optimum adhesion," The Journal of Adhesion, vol. 4, no. 2, pp. 123132, 1972.

[22] T. Hata, Y. Kitazaki, and T. Saito, "Estimation of the surface energy of polymer solids," The Journal of Adhesion, vol. 21, no. 3-4, pp. 177-194, 1987.

[23] C. Jongwannasiri, A. Khantachawana, P. Kaewtatip, N. Moolsradoo, and S. Watanabe "Fluorinated diamond-like carbon coatings by plasma based ion implantation for biomedical application," in Proceedings of the 2nd Biomedical Engineering International Conference (BMEiCON '09), pp. 286-290, Club Andaman Beach Resort, Phuket, Thailand, August 2009.

[24] M. A. Capano, N. T. McDevitt, R. K. Singh, and F. Qian, "Characterization of amorphous carbon thin films," Journal of Vacuum Science and Technology A, vol. 14, no. 2, pp. 431-435, 1996.

[25] J. Qi, J. B. Luo, S. Z. Wen, J. Wang, and W. Z. Li, "Mechanical and tribological properties of non-hydrogenated DLC films synthesized by IBAD," Surface and Coatings Technology, vol. 128-129, pp. 324-328, 2000.

[26] F. L. Freire Jr., G. Mariotto, R. S. Brusa, A. Zecca, and C. A. Achete, "Structural characterization of amorphous hydrogenated carbon and carbon nitride films deposited by 
plasma-enhanced CVD," Diamond and Related Materials, vol. 4, no. 4, pp. 499-502, 1995.

[27] M. Ishihara, T. Kosaka, T. Nakamura et al., "Antibacterial activity of fluorine incorporated DLC films," Diamond and Related Materials, vol. 15, no. 4-8, pp. 1011-1014, 2006.

[28] G. Q. Yu, B. K. Tay, Z. Sun, and L. K. Pan, "Properties of fluorinated amorphous diamond like carbon films by PECVD," Applied Surface Science, vol. 219, no. 3-4, pp. 228237, 2003.

[29] A. Bendavid, P. J. Martin, L. Randeniya, and M. S. Amin, "The properties of fluorine containing diamond-like carbon films prepared by plasma-enhanced chemical vapour deposition," Diamond and Related Materials, vol. 18, no. 1, pp. 66-71, 2009.

[30] R. K. Roy, H. W. Choi, J. W. Yi et al., "Hemocompatibility of surface-modified, silicon-incorporated, diamond-like carbon films," Acta Biomaterialia, vol. 5, no. 1, pp. 249-256, 2009.

[31] N. Moolsradoo and S. Watanabe, "Modification of tribological performance of DLC films by means of some elements addition," Diamond and Related Materials, vol. 19, no. 5-6, pp. 525-529, 2010.

[32] Z. Q. Yao, P. Yang, N. Huang, H. Sun, and J. Wang, "Structural, mechanical and hydrophobic properties of fluorine-doped diamond-like carbon films synthesized by plasma immersion ion implantation and deposition (PIII-D)," Applied Surface Science, vol. 230, no. 1-4, pp. 172-178, 2004.

[33] J. Hong, K. Nilsson Ekdahl, H. Reynolds, R. Larsson, and B. Nilsson, "A new in vitro model to study interaction between whole blood and biomaterials. Studies of platelet and coagulation activation and the effect of aspirin," Biomaterials, vol. 20, no. 7, pp. 603-611, 1999.

[34] C. L. Haycox and B. D. Ratner, "In vitro platelet interactions in whole human blood exposed to biomaterial surfaces: insights on blood compatibility," Journal of Biomedical Materials Research, vol. 27, no. 9, pp. 1181-1193, 1993.

[35] J. M. Grunkemeier, W. B. Tsai, C. D. McFarland, and T. A. Horbett, "The effect of adsorbed fibrinogen, fibronectin, von Willebrand factor and vitronectin on the procoagulant state of adherent platelets," Biomaterials, vol. 21, no. 22, pp. 22432252, 2000.

[36] W. J. Ma, A. J. Ruys, R. S. Mason et al., "DLC coatings: effects of physical and chemical properties on biological response," Biomaterials, vol. 28, no. 9, pp. 1620-1628, 2007.

[37] J. L. Bohnert and T. A. Horbett, "Changes in adsorbed fibrinogen and albumin interactions with polymers indicated by decreases in detergent elutability," Journal of Colloid And Interface Science, vol. 111, no. 2, pp. 363-377, 1986.

[38] I. Dion, X. Roques, C. Baquey, E. Baudet, B. B. Cathalinat, and N. More, "Hemocompatibility of Diamond-like Carbon coating," Biomedical Materials and Engineering, vol. 3, no. 1, pp. 51-55, 1993.

[39] I. Dion, C. Baquey, B. Candelon, and J. R. Monties, "Hemocompatibility of titanium nitride," International Journal of Artificial Organs, vol. 15, no. 10, pp. 617-621, 1992.

[40] B. D. Ratner, "Blood compatibility - a perspective," Journal of Biomaterials Science, Polymer Edition, vol. 11, no. 11, pp. 1107$1119,2000$.

[41] S. L. Goodman, S. L. Cooper, and R. M. Albrecht, "The effects of substrate-adsorbed albumin on platelet spreading," Journal of Biomaterials Science, Polymer Edition, vol. 2, no. 2, pp. 147159, 1991.

[42] A. L. Kaganov, J. Stamberg, and P. Synek, "Hydrophilized polyethylene catheters," Journal of Biomedical Materials Research, vol. 10, no. 1, pp. 1-7, 1976.
[43] K. Park and S. L. Cooper, "Importance of composition of the initial protein layer and platelet spreading in acute surfaceinduced thrombosis," Transactions of the American Society for Artificial Internal Organs, vol. 31, pp. 483-488, 1985.

[44] T. Duerig, A. Pelton, and D. Stöckel, "An overview of nitinol medical applications," Materials Science and Engineering A, vol. 273-275, pp. 149-160, 1999.

[45] J. H. Sui and W. Cai, "Mechanical and corrosion study of diamond-like carbon coating on NiTi alloys," Surface and Coatings Technology, vol. 201, no. 9-11, pp. 5121-5123, 2007.

[46] D. J. Wever, A. G. Veldhuizen, J. De Vries, H. J. Busscher, D. R. A. Uges, and J. R. Van Horn, "Electrochemical and surface characterization of a nickel-titanium alloy," Biomaterials, vol. 19, no. 7-9, pp. 761-769, 1998.

[47] C. Trepanier, M. Tabrizian, L'H. Yahia, L. Bilodeau, and D. L. Piron, "Improvement of the corrosion resistance of NiTi stents by surface treatments," Materials Research Society Symposia Proceedings, vol. 459, pp. 363-368, 1997.

[48] J. Lausmaa, L. Mattsson, U. Rolander, and B. Kasemo, "Chemical composition and morphology of titanium surface oxides," Materials Research Society Symposia Proceedings, vol. 55, pp. 351-359, 1986. 

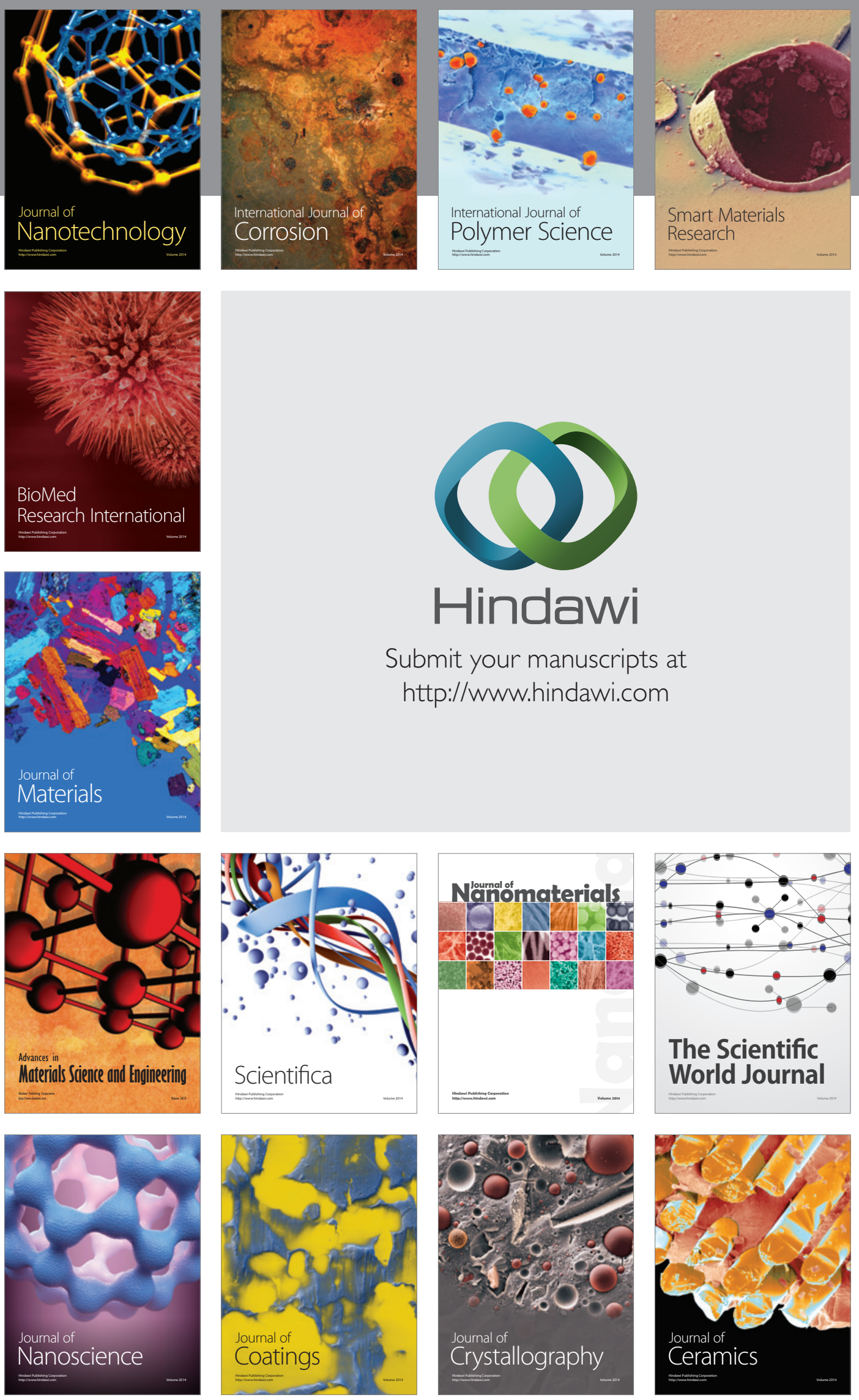

The Scientific World Journal

Submit your manuscripts at

http://www.hindawi.com

\section{World Journal}

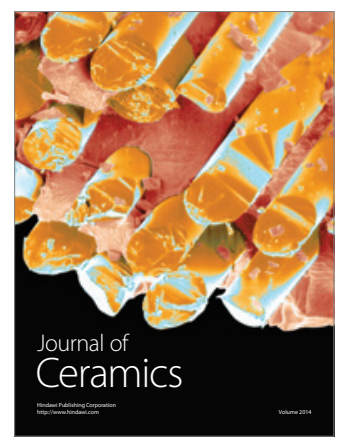

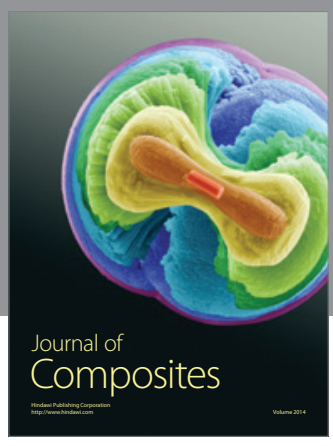
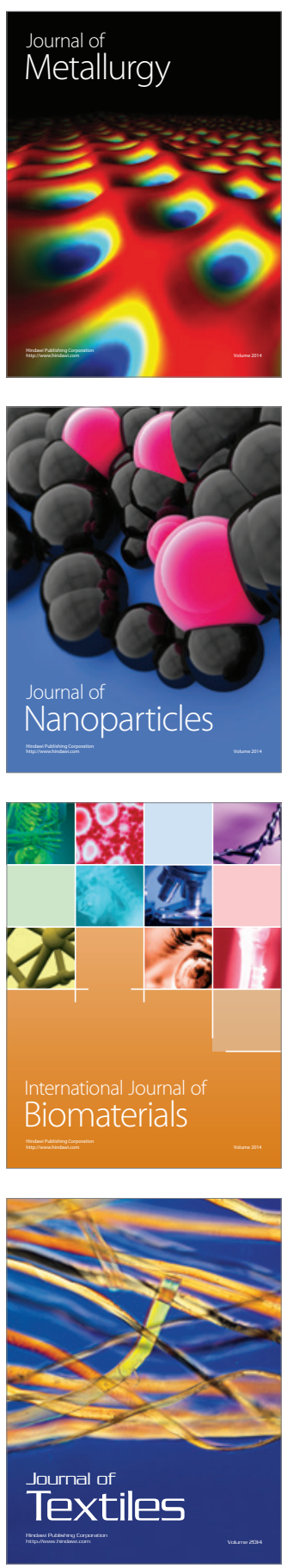